\title{
María Rosa Gudiño Cejudo, Educación higiénica y cine de la salud en México 1925-1960, México, El Colegio de México, 2016, 256 pp.
}

A finales del siglo XIX durante el porfiriato el tema de la higiene cobró importancia, sobre todo en el ámbito escolar y fue calificado como un tema central para educación pública. Se desplegó un importante programa de salud escolar que impulsaba la enseñanza, prevención, atención e investigación. El proyecto educativo porfirista consideraba que una educación moderna debía trasmitir hábitos de limpieza y salud, pues un país que tenía como paradigma la industrialización debía contar con ciudadanos sanos, limpios y trabajadores de allí la importancia que adquiría la higiene escolar.

El tema de la educación higiénica tiene sus inicios en el este espacio temporal, se desplegó fundamentalmente en las escuelas y los recursos que utilizó para difundir el discurso higienista fueron los libros escolares y los maestros como ejecutores de la enseñanza.

El siglo XX se ve impactado por el movimiento revolucionario de 1910 y tema de la educación higiénica queda en espera, pues mucho de lo realizado en años anteriores se abandonó. La década de los veintes marcada en especial por el gobierno Plutarco Elías Calles retomó el tema y le imprimió un especial sello.

El libro que reseñó y que lleva por título Educación higiénica y cine de salud en México 1925-1960, nos habla de los intentos por expandir la educación higiénica, cubre de manera especial un periodo de 35 años, que nos lleva por cuatro importantes décadas del siglo XX, que abarcan la reconstrucción nacional y el impulso del desarrollo industrial que llevaría a México a insertarse en un proceso de modernización económica.

$\mathrm{El}$ texto se estructura a partir tres momentos importantes marcados por fuertes y extensivas campañas de salud: la primera la Campaña Nacional de Enfermedades Venéreas (1927). La 
segunda, Salud para las Américas (1934-1950) y tercera, La Campaña Nacional contra el Paludismo. Estas campañas fueron analizadas en vinculación con la producción cinematográfica que se generó durante este período y justo en este punto quiero detenerme. La autora elige una novedosa e importante fuente: el cine. Los historiadores habitualmente nos concentramos en la documentación escrita resguardada en archivos, lo cual no está mal y es de gran utilidad, pero el recurrir a nuevas fuentes siempre enriquecerá el trabajo de investigación. Por tanto, al tener en nuestras manos un libro que toma una fuente poco explorada por los historiadores para su análisis, nos lleva a resultados y conclusiones importantes y a la gestación de nuevos conocimientos sobre la educación higiénica en México. La consulta de 200 cortometrajes nacionales y extranjeros, además de la revisión de folletería, revistas, carteles, prensa y una amplia bibliografía localizada archivos y filmotecas nacionales tales como son: el Archivo Histórico del Instituto Nacional de Salud Pública, Archivo Histórico de la Secretaría de Educación Pública, Archivo Histórico de la Secretaría de Salud. Acervo Filmográfico del Archivo Histórico de la Secretaría de Salud, Filmoteca de la Universidad Nacional Autónoma de México. Así como materiales localizados en Washington, D.C., Estados Unidos (National Archives of Record Administration, Colege Park y National Library of Congress nos hablan de un sustento sólido y amplio para escritura este libro.

La propaganda sanitaria con fines educativos se ha explorado poco por la historiografía en México, de allí la relevancia de este trabajo. La autora anota el porqué de su inclinación por el tema y cito "como un instrumento de persuasión motivaron mi interés por conocer y analizar esas formas habladas, escritas y actuadas para aconsejar a un público, al que generalmente se le consideró ingenuo y atrasado, que ser limpio, lavarse las manos, vacunarse, usar zapatos, ser cuidadoso de la vida sexual, aplicar insecticidas y tomar a tiempo 
sus medicinas les beneficiaría enormemente en la vida diaria y en la de sus descendientes” (Gudiño, 2016: 17).

Se formulan varias y yo diría muchas preguntas de investigación para guiar el texto, lo cual nos lleva a pensar en el gran interés y entusiasmo por el tema, que no es fácil de construir. Sin embargo, la autora logra de manera estupenda presentarnos a partir de un contexto nacional e internacional amplio, que va de 1925 a 1960, una problemática que se centra en la educación higiénica y que toma a la propaganda y en especial al cine como el medio para educar a una población con pocos recursos a su alcance para mejor su salud y combatir las enfermedades que se gestan en parte por su entorno social y cultural.

Los actores que vemos actuar en este escenario y cuya importancia, yo diría es igual ya que todos establecen una relación de alguna manera para lograr su objetivo. Aunque si tenemos como líder del proyecto al Estado Mexicano. Entre los que operan el proyecto estaban los médicos, enfermeras, maestros rurales, sanitaristas, rociadores, notificantes, dibujantes, directores de cine. Los casos de Walt Disney la Fundación Rockefeller son especiales en tanto que aportan dinero y una línea ideológica.

El libro se construye a partir de cinco capítulos en los que se muestran algunas fotografías que nos permiten acercarnos al espacio y tiempo en que fue generada la fotografía, pero sobretodo la problemática sanitaria. Un apartado de conclusiones y el citado de las fuentes primarias y secundarias que son expuestos a lo largo de 256 páginas. Su lectura es amena, interesante y nos adentra en el conocimiento de una temática novedosa por su tratamiento.

En el primer capítulo "Una mirada retrospectiva" la autora nos presenta un contexto histórico internacional que incluye momentos relevantes del siglo $\mathrm{XX}$, como lo fueron la depresión económica del año 1929, la Segunda Guerra Mundial, y el inicio de la Guerra Fría. El contexto nacional borda también momentos claves del siglo como los fueron la 
guerra cristera, el proyecto de educación socialistas del gobierno cardenista, la reforma agraria, la expropiación petrolera, el crecimiento población y urbano en especial de la ciudad de México. Todo ello a fin de explicar el marco político, económico y cultural en el que presenta y desarrolla el tema central del libro: las campañas de salud y sus instrumentos de educación higiénica.

Inicia en el año 1903 y enfatiza los años de 1907, 1908 y llega a finales del porfiriato con la mención de las Campañas para combatir la fiebre amarilla, la malaria, la tuberculosis y las enfermedades venéreas, a cargo del Consejo Superior de Salubridad. Buenos e importantes esfuerzos, pero estos se vieron interrumpidos por el movimiento armado. Los efectos de la guerra trajeron el aumento de epidemias, desnutrición y enfermedades, aumento de la mortalidad. Lo alcanzado por el gobierno de Porfirio Díaz se estancó. El año de 1916 bajo el gobierno de Venustiano Carranza se considera el tema sanitario y se realiza un balance sanitario titulado La higiene en México, después de la revolución era necesario un balance para implementar las acciones. El fuerte trabajo de los médicos para atender el tema sanitario y la creación de instituciones, dieron resultados, uno de los más destacados la creación de la Escuela de Salubridad y la Sección de Educación Higiénica y Propaganda. Había muestras de un Estado interesado en contar con ciudadanos sanos y de allí el apoyo.

La década de los veinte muestra el interés de los Estados Unidos por impulsar el modelo de campañas sanitarias en México y en especial la educación higiénica. Así se explica la presencia de la Fundación Rockefeller que desplegó médicos en los estados de Veracruz, Chiapas y Oaxaca.

La década de los treinta se distingue por la presencia de un enfoque social, es decir las enfermedades colectivas tiene múltiples causas, aquí se presentan destacas figuras de la 
medicina como son los doctores Alfonso Pruneda, Miguel Bustamante, Jesús Díaz barriga y antropólogo Miguel Othón de Mendizabal.

Para impulsar un programa de educación higiénica fue necesario desplegar imaginación y conocimiento de la realidad rural de México, participan para este fin la Secretaria de Educación Pública y el Departamento de Salubridad Pública. El planteamiento del Estado para apoyar el tema sanitario es el siguiente y cito "Ambas dependencias manejaron un discurso de renovación, sustentado en la idea de que un pueblo sano equivalía a una suma de individuos fuertes y vigorosos $\mathrm{y}$, por lo tanto, capaces de contribuir a la reconstrucción y desarrollo nacionales” (Gudiño: 41).

En el segundo capítulo "Educación Higiénica: Instrumentos y Actores” la autora nos presenta las modalidades que se diseñaron para impulsar la propaganda sanitaria: oral, gráfica y audiovisual. Estas acciones a cargo de la Sección de Educación Higiénica y Propaganda. En éste capítulo se puede conocer con detalle la diversa, creativa, ingeniosa y novedosa propaganda que se desplegó en el país. La idea era atender y cubrir todos los sentidos del receptor, éste podía ser el niño, la madre de familia, y los adultos. De allí que el formato oral se sostuvo con conferencias y programas de radio de salud, la mayoría dirigidos y elaborados por médicos, claro que, trasmitidos por locutores de radio, como el Tío Polito, que atendía trasmitía temas de salud para niños, otro programa muy conocido La escuela y el hogar. Uno de los destinatarios más importantes fueron los niños, ellos podían convertirse en detonadores de los aprendizajes sanitarios, de allí que la escuela fue un objetivo a cubrir. La Sección de Psicopedagogía y Educación Higiénica de la Secretaría de Educación Pública fue la encargada de esta promoción. Se incluyeron además carteles, folletos, botiquines médicos, y películas para ser difundidos en las escuelas. 
Los adultos recibieron otro tipo de enseñanzas pues se consideraba que ya tenían hábitos difíciles de cambiar, por ello utilizó se una propaganda más fuerte, específica e intensiva. Los programas de radio fueron importantes para este fin, aunados a los folletos, periódicos y carteles en el libro se presentas varias fotografías de estos materiales impresos.

El formato gráfico se valió de volantes, carteles y folletos, periódicos, hubo títulos importantes que divulgaban el mensaje higiénico de manera clara explicando las causas de la enfermedad, eran gratuitos y de fácil comprensión, algunos títulos: Mensajero de la salud, EI Sembrador y El Maestro Rural.

Una fuente importante que se utilizó fue el Museo de Higiene que incluía diversos materiales, su labor fue educativa, utilizó mapas, maquetas, imágenes, etc. sus destinatarios todo tipo de población.

El formato audiovisual incluyó al cine. Para esta investigación representó el soporte argumentativo más fuerte, se proyectaron películas estadounidenses y alemanas dobladas al español y por supuesto mexicanas. Para los años cuarenta se incluyen los cortometrajes de Walt Disney. La autora ofrece un importante listado de la filmografía mexicana y estadounidense en el apartado de referencias.

La posibilidad del éxito de la educación higiénica estaba en sus promotores y divulgadores: médicos, sanitaristas, intermediarios sanitarios y maestros rurales a estos hombres y mujeres con un verdadero apostolado la autora dedica varias páginas de este capítulo.

El tercer capítulo "Cine contra la Sífilis”, la autora aborda un tema que había sido una de las grandes preocupaciones de la salud pública en México, cito "Desde fines del siglo XIX, los médicos porfirianos opinaban que la sífilis era uno de los azotes de los hombres y causa de desgracias familiares” (Gudiño: 121). Para atender esta compleja problemática se optó por el cine. La autora seleccionó tres películas estadounidenses y una mexicana. A través de esta 
fuente se analizó la Campaña antivenérea de 1927. También presenta y cito "el contexto cimematográfico en el cual los filmes de temas médicos y de higiene adquirieron importancia y se convirtieron en instrumentos de educación higiénica de gran uso” (Gudiño, p. 122).

El cuarto capítulo "Salud para las Américas y Walt Disney", Se presenta un capítulo muy especial, por la conjunción de actores y de un especial contexto. En el año 1942 en pleno escenario de la Segunda Guerra Mundial, se celebró la XI Conferencia Sanitaria Panamericana y los Estados Unidos sumamente interesados como pocas veces en los temas sanitarios de América Latina. El invitado especial Nelson Rockefeller, presidente de la oficina del Coordinador de Asuntos Interamericanos, como parte de los resolutivos se acordó "que la defensa del continente en materia sanitaria era una prioridad para los países latinoamericanos” (Gudiño: 153). Un fuerte programa de educación higiénica se impulsaba bajo la dirección y tutela de los Estados Unidos, su nombre Health for the Américas o Salud para las Américas. De manera hábil y estratégica se optó por el cine para impulsar el programa sanitario destinado a Latinoamérica. Sus alcances serían mayores y su impacto fue decisivo. Tres destacadas figuras del cine norteamericano, fueron invitados: Walt Disney el famoso director y animador, Herbert Knapp, fotógrafo y Jack Chertok, productor. Se produjeron trece cortometrajes y varios documentales. No era cualquier proyecto era uno de los más importantes de la época, desplegado por Estados Unidos, al destinar el Instituto de Asuntos Interamericanos la cantidad de 2500000 dólares para el Programa de Cooperación de Salubridad y Saneamiento de México. Sus objetivos muy claros, atendían los siguientes puntos y cito: "1) dar a conocer entre la audiencia estadunidense las < bondades y atractivos> de los países de las <otras Américas>; 2) abrir nuevos mercados para sus filmes, y 3) filmar películas educativas para la audiencia latinoamericana, en dos temas específicos: salud y alfabetización” (Gudiño: 162). Por parte de México participaron también figuras relevantes 
del ámbito cinematográfico y educativos: el fotógrafo Gabriel Figueroa Mateos y la profesora Eulalia Guzmán, asisten a un seminario para opinar acerca de las historias de Disney para la campaña en América Latina, sus comentarios relevantes y la experiencia de estar en este espacio fue importante y enriquecedora para ambos actores. Aunque finalmente para la producción de Disney se promovió una muy particular imagen del mundo latinoamericano. El capítulo resulta más que atractivo no solo por la participación de un famoso director como es Walt Disney y su importante trayectoria en el cine para niños, sino por todo lo que implicó el uso del cine como una herramienta para la educación higiénica. Una lectura detallada del capítulo nos ofrecerá importante y novedosa información sobre el cine, la educación y la salud.

Por último, el capítulo V “A erradicar el paludismo: una versión cinematográfica mexicana”. Se analiza la Campaña Nacional de Erradicación del Paludismo, iniciada en el año de 1955, a cargo de la Secretaría de Salubridad y Asistencia fue promovida en todo el país. Los recursos propagandísticos fueron diversos, pero el más llamativo fue el cinematográfico, se realizaron una serie de cortometrajes en la Sección de Educación Higiénica de la Secretaría de Salubridad y Asistencia, destacan: Guerra al paludismo, Cruzada heroica, y Erradicación del paludismo en México. Por tanto, el cine fue utilizado como la principal estrategia de educación higiénica. Por demás novedosa y propositiva, siguió el camino de las campañas de la década de los cuarenta.

La autora nos muestra a lo largo de este capítulo varios momentos que se tejen a partir de la enfermedad: el paludismo. Así tenemos una explicación del padecimiento y sus manifestaciones; seguido de un puntual tratamiento de la Campaña Nacional de erradicación del paludismo en México, en este punto destacan dos figuras: el rociador y los notificadores, actores protagónicos, en sus manos estaban acciones determinantes para la campaña. Los 
siguientes apartados atienden el tema de la educación higiénica y del cine antipalúdico, y el cine de la erradicación. El texto se complementa y se enriquece con la serie de fotografías que se incluyen

En las últimas páginas del libro se presenta el punto dedicado al cine mexicano, que cierra de manera espléndida este importante libro al presentar la manera en que la política sanitaria mexicana atendió y enfrentó al paludismo, como lo escribe la autora: "la erradicación a la mexicana”.

El libro Educación higiénica y cine de salud en México 1925-1960, nos lleva a conocer y comprender la política sanitaria, impulsada por los gobiernos pos revolucionarios, en donde el tinte nacionalistas y autoritario de dejan ver, en un marco cuyo contexto esta permeado por tres de los acontecimientos mundiales más importantes del siglo XX: la depresión económica de 1929, la Segunda Guerra Mundial y el inicio de la Guerra Fría. En este espacio de tiempo y acontecimientos la autora nos introduce en los temas de la salud pública y nos lleva tomados de la mano del cine para hablarnos de tres importantes campañas de prevención y erradicación de enfermedades que afectaban la vida de los mexicanos, en su mayoría pobres y de zonas rurales.

Las campañas, la educación higiénica y el cine se entrelazan para ofrecernos un libro interesante, novedosos y propositivo. Su lectura se recomienda para todo lector interesado en los temas de la educación, el cine y la salud pública en México. Seguido de ver una película, por ejemplo: María Candelaria o Tierra de chicle. 